\title{
The effects of insulin therapy on maternal blood pressure and weight in women with gestational diabetes mellitus
}

Tiange Sun ${ }^{1 \dagger}$, Fanhua Meng $^{2+}{ }^{2 *}$, Shufei Zang ${ }^{1}$, Yue Li ${ }^{1}$, Rui Zhang ${ }^{1}$, Zhiyan $\mathrm{Yu}^{1}$, Xinmei Huang ${ }^{1}$, Fang Wang ${ }^{{ }^{*}}$, Liwen Zhang ${ }^{3^{*}}$ and Jun Liu ${ }^{1^{*}}$

\begin{abstract}
Background: Although insulin therapy achieves effective glycemic control, it may aggravate hyperinsulinemia. Nonetheless the benefits of insulin as first-line treatment for women with GDM are controversial. This work aimed to investigate the effect of insulin on maternal GDM.

Methods: This retrospective cohort study recruited 708 women with GDM of whom 616 underwent lifestyle intervention and 92 were prescribed insulin therapy. Differences in variables between the two groups were analyzed by univariate analysis and multivariate analysis. Propensity score matching was used to control for age, pre-pregnancy BMI, time and BP at GDM diagnosis, and family history of diabetes and hypertension. Paired sample test was applied to evaluate the changes in BP after intervention in the two groups of women.

Results: There was no significant difference in mode of delivery, newborn weight or incidence of macrosomia between women prescribed insulin and those who adopted lifestyle modifications. Insulin therapy was associated with a slight increase in maternal weight compared with the lifestyle intervention group and was attributed to short-term treatment (about 12 weeks). In addition, insulin therapy remarkably increased maternal blood pressure, an effect that persisted after matching age, pre-pregnancy BMI, time and BP at GDM diagnosis, and family history of diabetes and hypertension. Between commencing insulin therapy and delivery, systolic blood pressure significantly increased by $6 \mathrm{mmHg}(P=0.015)$ and diastolic blood pressure by $9 \mathrm{mmHg}(P<0.001)$. Increase in BP was significantly higher in the insulin group compared with the lifestyle intervention group $(P<0.001)$. Logistic regression analysis with enter selection confirmed that insulin therapy was closely correlated with development of gestational hypertension (GH).

Conclusions: This work suggested that short-term insulin therapy for GDM was associated with a slight increase in maternal weight but a significant risk of increasing maternal blood pressure.
\end{abstract}

Keywords: Gestational diabetes mellitus, Insulin therapy, Hypertension, Weight gain

\footnotetext{
*Correspondence: fangwang313@163.com; 13321837079@163.com; liujun@5thhospital.com

${ }^{\dagger}$ Tiange Sun and Fanhua Meng are co-first author of this manuscript.

'Department of Endocrinology, Shanghai Fifth People's Hospital, Fudan University, 801 Heqin Road, 200240 Shanghai, China

${ }^{3}$ Department of Obstetrics and Gynecology, Shanghai Fifth People's Hospital, Fudan University, 801 Heqin Road, 200240 Shanghai, China

Full list of author information is available at the end of the article
}

(C) The Author(s). 2021 Open Access This article is licensed under a Creative Commons Attribution 4.0 International License, which permits use, sharing, adaptation, distribution and reproduction in any medium or format, as long as you give appropriate credit to the original author(s) and the source, provide a link to the Creative Commons licence, and indicate if changes were made. The images or other third party material in this article are included in the article's Creative Commons licence, unless indicated otherwise in a credit line to the material. If material is not included in the article's Creative Commons licence and your intended use is not permitted by statutory regulation or exceeds the permitted use, you will need to obtain permission directly from the copyright holder. To view a copy of this licence, visit http://creativecommons.org/licenses/by/4.0/ The Creative Commons Public Domain Dedication waiver (http://creativecommons.org/publicdomain/zero/1.0/) applies to the data made available in this article, unless otherwise stated in a credit line to the data. 


\section{Introduction \\ Background}

Gestational diabetes mellitus (GDM) is defined as "diabetes diagnosed in the second or third trimester of pregnancy that was not clearly overt diabetes prior to gestation" [1]. With a greater prevalence of obesity and sedentary lifestyle, the prevalence of GDM is increasing globally. GDM is associated with a higher risk of serious complications for the mother (preeclampsia, caesarean section and development of type 2 diabetes) and the offspring (fetal macrosomia and childhood obesity) [2, 3-6].

Development of GDM is generally associated with overweight or obesity [7], and insulin resistance is the major pathophysiologic feature of women with GDM. To date, three classes of drugs have been recommended by the American Diabetes Association (ADA) for glycemic control in women with GDM. Insulin is first-line treatment. Metformin and glyburide should be used only as second-line treatment since both can cross the placenta to the fetus. Glyburide has been reported to be associated with a higher rate of neonatal hypoglycemia and macrosomia than insulin or metformin [8] although metformin may lead to nutrient restriction of glucose and amino acids to the fetus [9]. Exposure of the fetus to metformin may result in rapid growth after birth and a higher body mass index (BMI) by mid-childhood (5 to 9 years), effects associated with long-term metabolic consequences in later life such as obesity, type 2 diabetes, and cardiovascular disease [10]. Insulin is considered safe for the fetus since it does not cross the placenta to a measurable extent and is currently the first-line recommended treatment for GDM. Nonetheless the maternal effects of insulin therapy have not been studied. In addition, insulin may not improve the pathophysiologic features of women with GDM due to its risk of hyperinsulinemia which causes increased sodium reabsorption from the renal tubules, renin secretion, and sympathetic nervous activity [11].

This retrospective cohort study aimed to investigate the maternal and neonatal outcomes of insulin therapy. We established that insulin therapy for women with GDM was safe for the fetus, but that short term administration led to mild maternal weight gain and significantly increased BP.

\section{Research design and methods}

This was a retrospective cohort study. From May 2013 to July 2019, we recruited all women with GDM at the Gestational Diabetes Mellitus Care Center of the Fifth People's Hospital of Shanghai, Fudan University. The health card of all pregnant women was obtained from 10 to 12 weeks' gestation and included information about age, last menstruation, method of conception, parity, obstetric history, family history of diabetes, previous history of GDM, and pre-pregnancy weight. Subsequently at the first visit, at the time of oral glucose tolerance testing (OGTT) and one week prior to delivery, blood pressure (BP), weight, blood count (Sysmex XN9000, Japan), and biochemistry results (Cobas 8000, Roche, Switzerland) were recorded. Blood tests were performed in the morning after an overnight fast of at least $8 \mathrm{~h}$. BP was measured on two occasions $4 \mathrm{~h}$ apart. BMI was calculated as weight in kilograms divided by the square of the height in meters. Total gestational weight gain (GWG) and rate of weight gain during intervention was categorized according to the 2009 Institute of Medicine recommendations [12] as (1) inadequate weight gain; (2) adequate weight gain; (3) excessive weight gain.

Weighing scale was provided by Guangzhou GRG metrology and test CO. LTD, China (RGZ - 120). All women removed their shoes and heavy clothing prior to weight measurement. Blood pressure was measured using an automated sphygmomanometer (HEM - 7124) and recorded in both arms with the higher value being recorded. Normal weight women used a standard cuff $(24 \mathrm{~cm}$ in length $12 \mathrm{~cm}$ in width) and overweight women an extended and widened cuff $(64 \mathrm{~cm}$ in length $17 \mathrm{~cm}$ in width). Measurements were recorded with women seated in a chair with back support, their arm supported at heart level and after a minimum of 5 min rest. Weighing scale and automated sphygmomanometers were calibrated every 6 months and all measurements were taken by the same outpatient nurse using the same type of equipment. In the presence of raised $\mathrm{BP}$ or a diagnosis of GDM, routine obstetric examination was performed every 2 to 4 weeks in the outpatient clinic until 34 weeks' gestation and thereafter every week.

Gestational hypertension (GH) was defined as a systolic blood pressure $(\mathrm{SBP}) \geq 140 \mathrm{mmHg}$ and/or a diastolic blood pressure (DBP) $\geq 90 \mathrm{mmHg}$ on two occasions at least $4 \mathrm{~h}$ apart after 20 weeks of gestation in a woman with previously normal blood pressure [13].

All subjects with the exception of those diagnosed with overt diabetes or GDM in early pregnancy underwent routine screening for GDM at 24-28 weeks' gestation according to a $75 \mathrm{~g}$ OGTT. A diagnosis of GDM was based on American Diabetes Association (ADA) diagnostic criteria.

The values for Homeostatic Model Assessment of Insulin Resistance (HOMA - IR) and Homeostatic Model Assessment of islet $\beta$ cell function (HOMA - $\beta$ ) were determined from fasting plasma glucose and insulin concentration (Electrochemiluminescence, Cobas e602, Germany) [14]. Area under blood glucose (BG) curve was roughly calculated as $\frac{1}{2} \times($ fastingbloodglucose $(\mathrm{FBG})+$ $1 \mathrm{~h} \mathrm{BG})+\frac{1}{2} \times(1 \mathrm{~h} \mathrm{BG}+2 \mathrm{~h} \mathrm{BG})$.

Mothers with GDM were recommended to implement lifestyle modifications immediately on diagnosis of GDM 
and to continue until delivery. The time of GDM diagnosis was defined as the week of pregnancy in which changes were initiated. Women with GDM were advised to undertake a brisk 30 min walks at least three days per week along with dietary modifications and weight management. If glycemic control did not achieve the targets recommended by the Fifth International Workshop Conference on GDM (Fasting glucose, $5.3 \mathrm{mmol} / \mathrm{L}$ or $1 \mathrm{~h}$ postprandial glucose, $7.8 \mathrm{mmol} / \mathrm{L}$ or $2 \mathrm{~h}$ postprandial glucose, $6.7 \mathrm{mmol} / \mathrm{L}$ ) [15] after one week of lifestyle intervention, insulin therapy was commenced and continued along with lifestyle modifications until delivery according to ADA recommendations. Changes in weight and blood pressure were monitored from the time of GDM diagnosis until one week before delivery.

After delivery, data including gestational age at delivery, treatment protocol for lowering glycemia, birth weight, and gender of the neonate were recorded by medical staff.

Women were excluded from the study for any of the following: (1) pre-existing DM; (2) chronic hypertension; (3) renal disease history; (4) multiple gestation; (5) serious liver dysfunction (alanine transaminase above 2.5 times upper limit) and renal dysfunction (estimated Glomerular Filtration Rate below $\left.90 \mathrm{ml} / \mathrm{min} / 1.73 \mathrm{~m}^{2}\right)$. Finally, 708 women with GDM were entered into the analysis. Retrospective analysis processes are shown in Fig. 1.

\section{Statistical analysis}

Descriptive statistics for studied variables are presented as mean \pm standard deviation (SD) for normally distributed variables, median (interquartile range (IQR)) for non- normally distributed variables, and frequency (percentage) for categorical variables. Student's $t$ - test or MannWhitney $U$ test was used to identify difference in mean between groups. HOMA-IR and HOMA- $\beta$ were log transformed previously for $t$ tests. To eliminate the confounding effects on BP, a propensity score matching (PSM) method was employed to match variables of age, prepregnancy BMI, time (weeks) and BP at GDM diagnosis, family history of diabetes and hypertension. Matching tolerance was 0.02. Linear correlation of BP and other continuous variables was assessed by Pearson correlation analysis. Logistic regression analysis was performed with $\mathrm{GH}$ classified in a binary manner (presence/absence) as the dependent variable. Insulin therapy (categorized as present or absent) and other possible risk factors were entered into logistic regression analysis. Effect estimates are reported along with $O R$ value, $95 \% C I$ and $P$ value. Changes to BP after intervention (from the time of GDM diagnosis to one week before delivery) were subjected to paired sample test. All analyses were performed using SPSS 24.0 (IBM SPSS lnc, Chicago, IL, USA). A two-tailed $P$ value $<0.05$ was considered statistically significant.

\section{Results}

Characteristics of subjects in lifestyle intervention group and insulin therapy group in full cohort

In women diagnosed with GDM, Treatment with insulin was added to the diet regimen after one week if fasting and postprandial blood glucose didn't achieve the target. In this study, 92 women (12.9\%) required supplementary insulin therapy in addition to lifestyle modification and

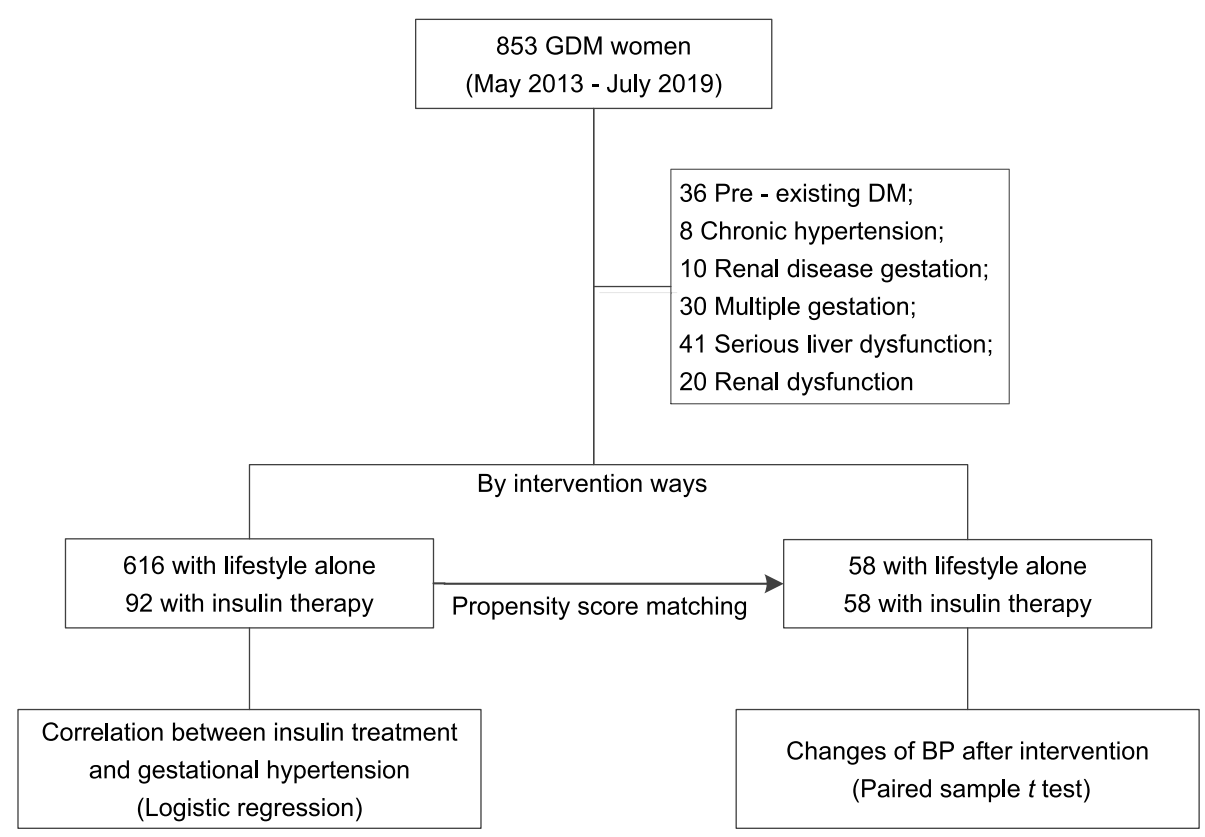

Fig. 1 Flowchart of the study. GDM, gestational diabetes mellitus; GH, gestational hypertension 
616 women $(87.1 \%)$ required lifestyle modification alone. Table 1 illustrated mothers with insulin treatment were more likely to have family history of diabetes or lower HOMA - $\beta$ (94.90 (52.05-259.19) vs. 295.85 (162.47663.78), $P<0.001)$ comparing with those without. There were no significant differences in pre-pregnancy BMI, HOMA-IR, serum lipid parameters, or SBP and DBP at baseline between the two groups. One week before delivery, women treated with insulin had a much higher BMI $\left(30.9 \pm 4.5\right.$ vs. $\left.28.4 \pm 3.5 \mathrm{~kg} / \mathrm{m}^{2}, P=0.020\right)$, SBP $(131 \pm 13$ vs. $124 \pm 13 \mathrm{mmHg}, P=0.005)$, $\mathrm{DBP}(80 \pm 8$ vs. $74 \pm 9$ $\mathrm{mmHg}, P=0.007)$, and incidence of GH ( $31.0 \%$ vs. $11.7 \%$, $P=0.001$ ). Nonetheless the level of excessive weight gain showed no significant difference even though women prescribed insulin had a higher BMI than those adopting only lifestyle modifications (Table 1). There were statistically significant changes to DBP in women prescribed insulin therapy. Mean DBP increased from $70 \pm 8 \mathrm{mmHg}$ to $80 \pm$ $8 \mathrm{mmHg}$, an increase of $9 \mathrm{mmHg}$ ( $95 \% \mathrm{CI}: 6-12 \mathrm{mmHg}, P$ $<0.001)$, and SBP from $124 \pm 11 \mathrm{mmHg}$ to $131 \pm 13$ $\mathrm{mmHg}$, an increase of $6 \mathrm{mmHg}$ (95\% CI: $1-11 \mathrm{mmHg}$, $P=0.015)$. In comparison, in women with lifestyle intervention alone, mean SBP increased by $4 \mathrm{mmHg}$ (95\% CI: $2-6 \mathrm{mmHg}, P<0.001)$ and DBP by $5 \mathrm{mmHg}$ ( $95 \% \mathrm{CI}: 4-$ $7 \mathrm{mmHg}, P<0.001)$. Difference in changes to DBP (9 $\mathrm{mmHg}$ vs. $5 \mathrm{mmHg}, P=0.032$ ), not SBP (6 mmHg vs. $4 \mathrm{mmHg}, P=0.529)$ was significant between women prescribed insulin and those not. Finally, there was no difference between time of intervention for hyperglycemia (12.3 \pm 1.6 vs. $12.6 \pm 3.1$ weeks, $P=0.628$ ), glycemic control (FBG $4.39 \pm 0.23$ vs. $4.66 \pm 0.33 \mathrm{mmol} / \mathrm{L}, P=0.912 ; 1 \mathrm{~h} \mathrm{BG}$ $7.14 \pm 1.23$ vs. $7.61 \pm 1.09 \mathrm{mmol} / \mathrm{L}, P=0.175 ; 2 \mathrm{~h} \mathrm{BG}$ $6.98 \pm 1.31$ vs. $6.79 \pm 1.22 \mathrm{mmol} / \mathrm{L}, P=0.614$ and $\mathrm{HbA} 1 \mathrm{c}$ $5.2 \pm 0.6$ vs. $5.4 \pm 0.4 \%, P=0.566$ at delivery), delivery mode, preterm, newborn weight, or incidence of macrosomia between women with insulin and without (Table 1).

\section{Comparison of parameters between women with lifestyle intervention alone and those prescribed insulin therapy after PSM}

To eliminate confounding effects on BP, a PSM method was employed to match variables of age, pre-pregnancy BMI, time (weeks) and BP at GDM diagnosis, family history of diabetes and hypertension. After matching, there were no significant differences in glycemic control, intervention time frame for glycemic control, the ratio of excessive weight gain, delivery mode, newborn weight or incidence of macrosomia between women with different intervention ways. Nonetheless there remained a higher incidence of $\mathrm{GH}(38.3 \%$ vs. $17.2 \%, P=0.028)$, and increased BMI $\left(30.4 \pm 4.7\right.$ vs. $\left.28.8 \pm 2.2 \mathrm{~kg} / \mathrm{m}^{2} P=0.030\right)$, SBP $(131 \pm 12$ vs. $124 \pm 9 \mathrm{mmHg}, P=0.043)$ and DBP ( $80 \pm 11$ vs. $71 \pm 10 \mathrm{mmHg}, P=0.011$ ) as time of delivery approached in women with insulin therapy compared with those with lifestyle intervention (Table 1). Paired sample $t$ test revealed that changes to SBP and DBP in women prescribed insulin were statistically significant. SBP increased from $125 \pm 11$ to $131 \pm 12 \mathrm{mmHg}$, an increase of $6 \mathrm{mmHg}$ ( $95 \% \mathrm{CI}: 1-12 \mathrm{mmHg}, P=0.015$ ), and DBP from $71 \pm 10$ to $80 \pm 11 \mathrm{mmHg}$, an increase of 9 mmHg (95\% CI: 6-12 mmHg, $P<0.001)$ (Fig. 2a). On the contrary, in women who adopted only lifestyle modifications, changes to SBP $(P=0.812)$ and DBP $(P=$ 0.089 ) were not significant (Fig. $2 b$ ). In addition, there were significant differences in the elevated SBP $(P<$ $0.001)$ and DBP between the two groups $(P<0.001)$ (Fig. 2c).

\section{Association of blood pressure with metabolic parameters $(n=503)$}

As shown in Table 2, BP in the week of performing OGTT was closely associated with HOMA-IR $(r=0.25$, $P=0.026)$ and pre-pregnancy BMI $(r=0.21, P=0.039)$. SBP at the time of delivery had a significant positive correlation with $1 \mathrm{~h} \mathrm{BG}(r=0.24, P=0.010)$, HbA1c $(r=$ $0.25, P=0.010)$, area under BG curve $(r=0.35, P<$ $0.001)$, BMI $(r=0.39, P<0.001)$, and total GWG $(r=$ $0.22, P=0.029)$.

\section{Insulin therapy was closely associated with development} of $\mathrm{GH}(n=512)$

Logistic regression analysis with enter selection showed that insulin therapy was closely correlated with development of $\mathrm{GH}(O R=6.33 ; 95 \% \mathrm{CI}, 1.17$ to 34.09 vs. the lifestyle intervention, $P=0.032$ ) corrected by history of hypertension, $2 \mathrm{~h}$ BG and total GWG. The same result was obtained when rate of weight gain during intervention instead of total GWG was entered into the model $(O R=6.65$; $95 \% \mathrm{CI}, 1.14$ to 38.65 vs. the lifestyle intervention, $P=0.035$ ) (Table 3 ).

\section{Discussion}

Insulin is recommended as first-line treatment for hyperglycemia in GDM by the ADA and many other associations. In this retrospective cohort study, we assessed the effect of insulin therapy on mothers with GDM and their fetus. Insulin therapy for about 12 weeks had a mild effect on maternal weight although it markedly increased BP. To avoid confounding, a PSM method was applied and revealed that the effect of insulin on maternal BP persisted.

Previous studies have evaluated the effects of insulin versus oral anti-diabetic drugs for treatment of GDM. Compared with oral anti-diabetic drugs, insulin has been associated with higher weight gain in GDM women [16, 17]. Nonetheless in infants, no significant differences in risk of perinatal death, being born large-for-gestational 
Table 1 Characteristics of women with GDM in lifestyle intervention group and insulin therapy group

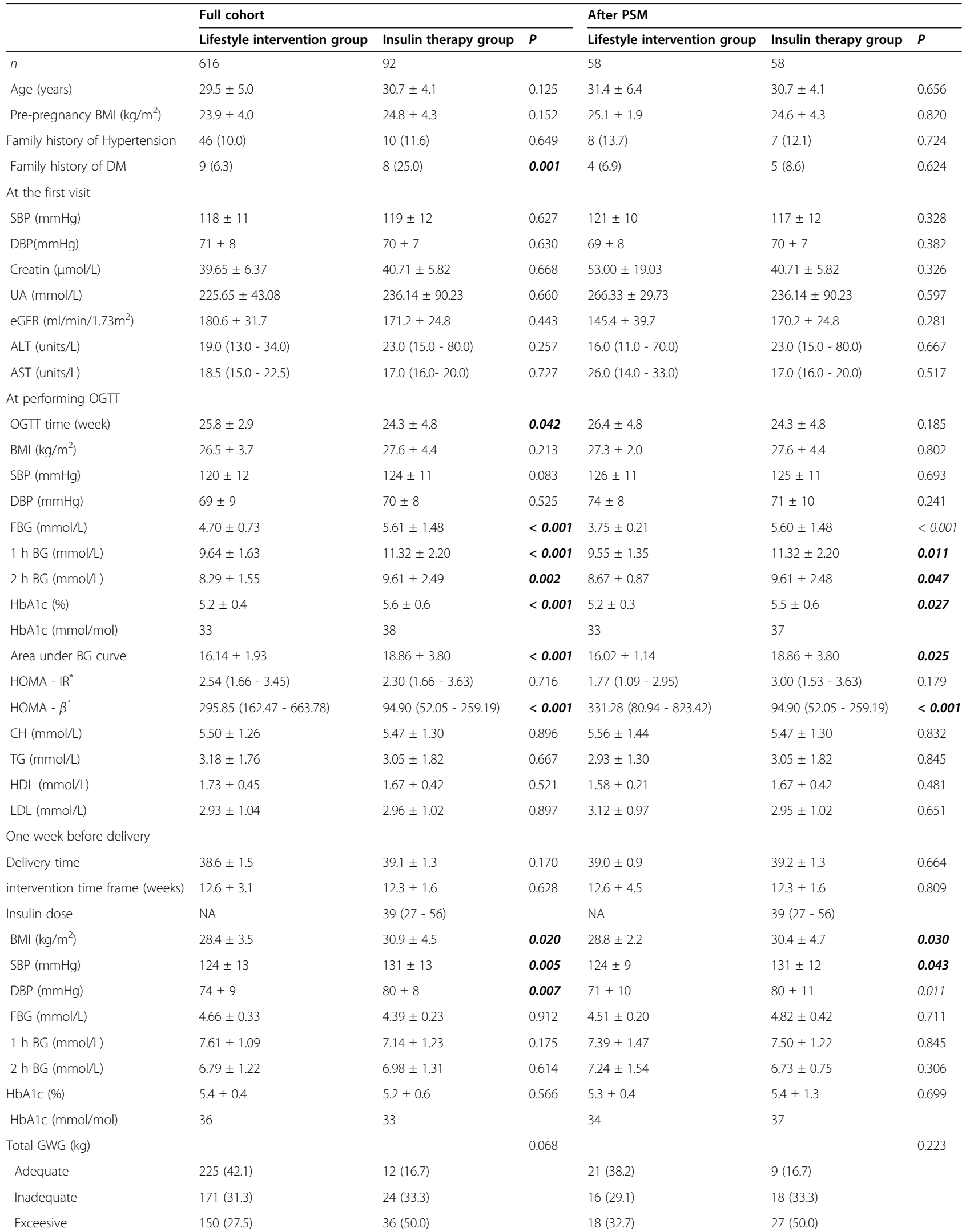


Table 1 Characteristics of women with GDM in lifestyle intervention group and insulin therapy group (Continued)

\begin{tabular}{|c|c|c|c|c|c|c|}
\hline & \multicolumn{3}{|l|}{ Full cohort } & \multicolumn{3}{|l|}{ After PSM } \\
\hline & Lifestyle intervention group & Insulin therapy group & $P$ & Lifestyle intervention group & Insulin therapy group & $P$ \\
\hline \multicolumn{2}{|c|}{ Rate of weight gain after OGTT $\left(\mathrm{kg} \mathrm{week}^{-1}\right)$} & & 0.345 & & & 0.563 \\
\hline Adequate & $84(28.6)$ & $12(11.8)$ & & $18(32.7)$ & $16(30.2)$ & \\
\hline Inadequate & $72(24.5)$ & $15(29.4)$ & & $14(25.5)$ & $6(11.3)$ & \\
\hline Exceesive & $138(46.9)$ & $60(58.8)$ & & $23(41.8)$ & $31(58.5)$ & \\
\hline Gestational hypertension & $72(11.7)$ & $20(31.0)$ & 0.001 & $12(17.2)$ & $26(38.3)$ & 0.028 \\
\hline Caesarean section & $280(68.3)$ & $46(63.9)$ & 0.602 & $28(48.3)$ & $32(56.5)$ & 0.449 \\
\hline Fetal sex (female) & $310(49.1)$ & $22(37.9)$ & 0.260 & $28(50.9)$ & $21(37.5)$ & 0.321 \\
\hline Preterm & $14(4.7)$ & $2(6.3)$ & 0.779 & $3(5.5)$ & $3(5.3)$ & 0.932 \\
\hline Newborn weight (g) & $3484.5 \pm 488.7$ & $3592.1 \pm 638.5$ & 0.260 & $3607.5 \pm 392.1$ & $3592.1 \pm 638.5$ & 0.938 \\
\hline Macrosomia & $62(14.3)$ & $10(15.2)$ & 0.796 & $9(16.3)$ & $8(15.1)$ & 0.901 \\
\hline
\end{tabular}

Data are mean $\pm \mathrm{SD}$, median (interquartile range) or $\mathrm{n}(\%)$, Log transformed for $\mathrm{t}$ test*

GDM gestational diabetes mellitus; Cr creatinine; UA uric acid; ALT alanine aminotransferase; AST aspartate aminotransferase; GWG gestational weight gain; $S B P$ systolic blood pressure; DBP diastolic blood pressure; eGFR estimated glomerular filtration rate; PSM propensity score matching

PSM to even the variables of age, pre-pregnancy BMI, time (weeks) and BP at GDM diagnosis, family history of diabetes and hypertension, match tolerance was 0.02

age $[18,19]$ or serious neonatal outcomes $[20,21]$ have been reported. Insulin resistance/hyperinsulinemia is largely attributed to obesity, a vital physiological character of GDM. Although insulin therapy achieves effective glycemic control, it may aggravate hyperinsulinemia.

Studies that have compared the effects on mothers with GDM and/or their fetus of insulin and lifestyle intervention showed no difference in weight gain between the two interventions. Our study retrospectively analyzed the effects of insulin therapy on maternal and neonatal outcomes and consistent with other studies found no difference in delivery mode, preterm delivery, or being born with macrosomia [22, 23].

It is generally considered that insulin therapy may induce weight gain in diabetic patients [24, 25]. Physiological fluctuations in insulin play a critical role in the balance between energy storage and energy consumption. Insulin acts as an anabolic hormone to reduce lipolysis and protein catabolism and promote lipogenesis and protein formation. Studies in humans and mice have postulated that over-replacement of insulin in patients with diabetes produces a general anabolic effect that leads to increased fat accumulation and weight gain [24]. Another mechanism proposed is that exogenous insulin first enters the peripheral tissues, such as adipose tissue and muscle tissue, resulting in increased fat synthesis. This leads to a cluster of ectopic fat accumulation and insulin resistance. In our cohort study, the length of insulin treatment was only about 12 weeks in women with GDM. That didn't lead to excessive weight gain in such women, however they had a higher BMI before delivery than those adopting lifestyle modifications alone. The results hinted that short-term use of insulin results in a mild increase in weight, but if administered for longer than 12 weeks the adverse effect might be aggravated.

Niromanesh et al. [26] reported that pregnant women prescribed insulin therapy had higher BP and weight gain than those given metformin. Our study showed that

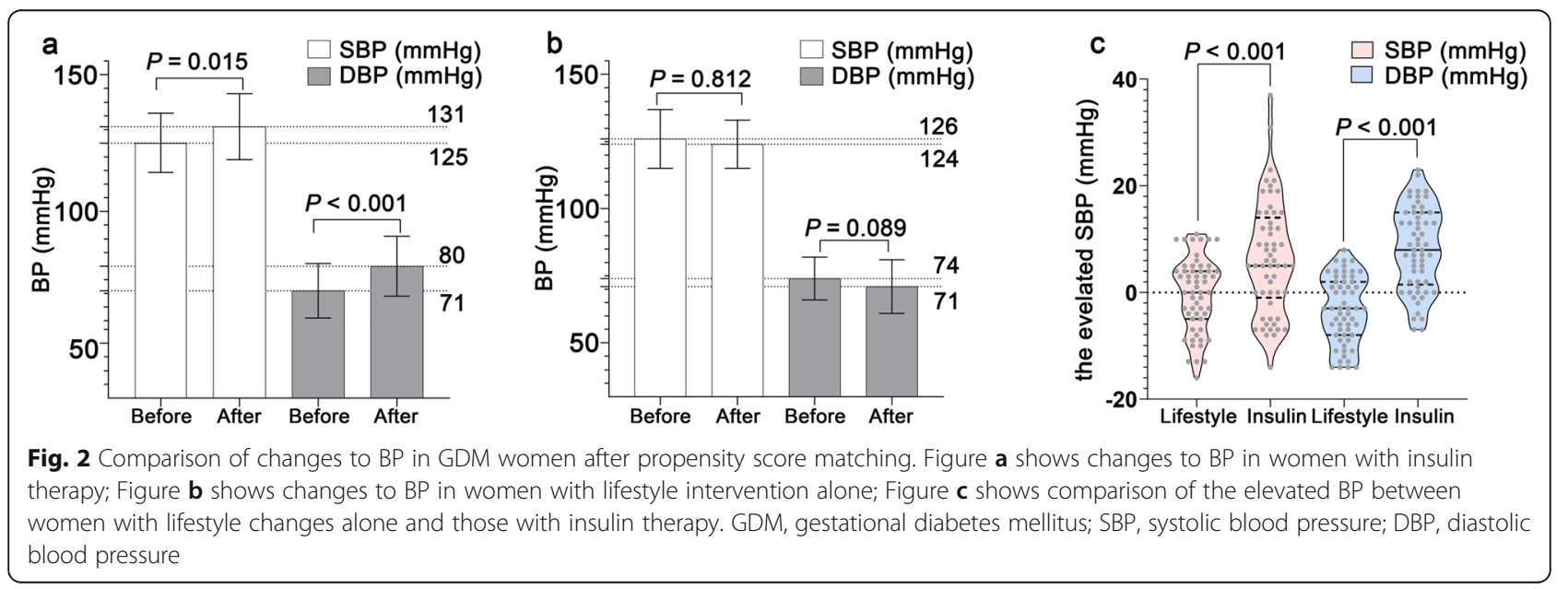


Table 2 The correlation analysis of blood pressure and other variables $(n=503)$

\begin{tabular}{|c|c|c|c|c|c|c|c|c|}
\hline & \multicolumn{4}{|c|}{ At OGTT } & \multicolumn{4}{|c|}{ Approaching delivery } \\
\hline & SBP & $P$ & DBP & $P$ & SBP & $P$ & DBP & $P$ \\
\hline Age (years) & -0.05 & 0.620 & -0.16 & 0.101 & -0.02 & 0.840 & -0.10 & 0.321 \\
\hline $\begin{array}{l}\text { Pre-pregnancy BMI (kg/m2)Pre-pregnancy BMI (kg/ } \\
\text { m2) }\end{array}$ & 0.21 & 0.039 & 0.23 & 0.019 & 0.21 & 0.030 & 0.15 & 0.140 \\
\hline \multicolumn{9}{|l|}{ At performing OGTT } \\
\hline $\mathrm{BMI}(\mathrm{kg} / \mathrm{m} 2) \mathrm{BMI}(\mathrm{kg} / \mathrm{m} 2)$ & 0.24 & 0.025 & 0.21 & 0.059 & 0.35 & $<.001$ & 0.33 & 0.002 \\
\hline $\mathrm{FBG}(\mathrm{mmol} / \mathrm{L})$ & 0.14 & 0.172 & -0.08 & 0.437 & 0.09 & 0.390 & 0.16 & 0.126 \\
\hline $1 \mathrm{~h} \mathrm{BG}(\mathrm{mmol} / \mathrm{L})$ & 0.03 & 0.777 & -0.07 & 0.455 & 0.24 & 0.010 & 0.15 & 0.124 \\
\hline $2 \mathrm{~h} \mathrm{BG}(\mathrm{mmol} / \mathrm{L})$ & -0.03 & 0.761 & -0.08 & 0.41 & 0.18 & 0.070 & 0.11 & 0.253 \\
\hline $\mathrm{HbA1c}(\%)$ & 0.17 & 0.083 & 0.10 & 0.329 & 0.25 & 0.010 & 0.14 & 0.178 \\
\hline Area under BG curve & 0.07 & 0.498 & -0.05 & 0.628 & 0.35 & $\begin{array}{l}< \\
0.001\end{array}$ & 0.23 & 0.028 \\
\hline HOMA - IR* HOMA - IR* & 0.25 & 0.026 & 0.16 & 0.162 & 0.07 & 0.530 & 0.11 & 0.314 \\
\hline HOMA - $\beta^{*}$ HOMA - $\beta^{*}$ & -0.03 & 0.788 & 0.17 & 0.156 & -0.19 & 0.120 & -0.18 & 0.132 \\
\hline $\mathrm{CH}(\mathrm{mmol} / \mathrm{L})$ & -0.01 & 0.959 & -0.08 & 0.421 & 0.04 & 0.690 & 0.01 & 0.896 \\
\hline TG $(\mathrm{mmol} / \mathrm{L})$ & 0.09 & 0.366 & 0.16 & 0.114 & 0.18 & 0.070 & 0.15 & 0.126 \\
\hline $\mathrm{HDL}(\mathrm{mmol} / \mathrm{L})$ & -0.12 & 0.246 & -0.04 & 0.685 & -0.02 & 0.840 & -0.04 & 0.677 \\
\hline LDL (mmol/L) & 0.01 & 0.947 & -0.10 & 0.336 & 0.02 & 0.850 & 0.00 & 0.979 \\
\hline \multicolumn{9}{|l|}{ One week before delivery } \\
\hline BMI (kg/m2) & NA & NA & NA & NA & 0.39 & $\begin{array}{l}< \\
0.001\end{array}$ & 0.29 & 0.030 \\
\hline Total GWG (kg) & NA & NA & NA & NA & 0.22 & 0.029 & 0.12 & 0.224 \\
\hline Rate of weight gain after intervention (kg week-1) & NA & NA & NA & NA & 0.07 & 0.950 & 0.036 & 0.751 \\
\hline
\end{tabular}

Log transformed for the correlation analysis*

GWG gestational weight gain; SBP systolic blood pressure; DBP diastolic blood pressure

Table 3 Logistic regression analysis with enter selection for presence/absence $\mathrm{GH}(n=512)$

\begin{tabular}{lllll}
\hline & $\boldsymbol{B}$ & $\mathbf{O R}$ & $\mathbf{9 5 \%} \mathbf{C l}$ & $\boldsymbol{P}$ \\
\hline Insulin therapy & 1.85 & 6.33 & $1.17-34.09$ & $\mathbf{0 . 0 3 2}$ \\
History of hypertension & 3.10 & 22.4 & $2.66-188.96$ & $\mathbf{0 . 0 0 4}$ \\
2h BG (mmol/L) & 0.63 & 1.88 & $1.10-3.21$ & $\mathbf{0 . 0 2 0}$ \\
Total GWG (kg) & & & & \\
Adequate & reference & & & 0.228 \\
Inadequate & -1.24 & 0.29 & $0.04-2.18$ & $\mathbf{0 . 0 1 0}$ \\
Excessive & 2.07 & 7.89 & $1.63-38.15$ & $\mathbf{0 . 0 3 5}$ \\
Insulin therapy & 1.89 & 6.65 & $1.14-38.65$ & $\mathbf{0 . 0 0 4}$ \\
History of & 4.18 & 65.13 & $3.81-703.54$ & $\mathbf{0 . 0 9 9}$ \\
hypertension & & & & \\
2h BG (mmol/L) & 0.50 & 1.65 & $0.91-2.99$ & $\mathbf{0 . 9 9 2}$ \\
The rate of weight gain during intervention (kg week & & & $\mathbf{0 . 0 4 6}$ \\
Adequate & reference & & & \\
Inadequate & 0.02 & 1.02 & $0.06-18.50$ & \\
Excessive & 2.87 & 17.56 & $1.05-192.42$ & \\
\hline
\end{tabular}

$\overline{\text { GH gestational hypertension; BG blood glucose; GWG gestational weight gain }}$ insulin therapy increased BP, and BP was positively associated with BMI and HOMA-IR. Wang F et al. [27] demonstrated that insulin resistance or elevated fasting insulin concentration was independently associated with an exacerbated risk of hypertension in the general population. Hyperinsulinemia/insulin resistance may induce sodium reabsorption by the distal nephron segments [28], resulting in increased release of angiotensin II, the main effector peptide of the renin-angiotensin system [29], and enhanced sympathetic activity, vascular resistance [30,31], and endothelial dysfunction [29]. Ana et al. [32] aimed to elucidate the mechanism by which hyperinsulinemia increases BP during pregnancy using euglycemic hyperinsulinemia and normal pregnant Sprague-Dawley rats. The results demonstrated that sustained euglycemic hyperinsulinemia could raise blood pressure in pregnancy, independent of changes in glycemia. Wang et al. [33] reported similar results in Sprague-Dawley rat models in which hyperinsulinemia rather than insulin resistance played an important role in blood pressure elevation. The reduction of urinary sodium excretion also appeared to be an important mediator to link hyperinsulinemia and blood pressure. 
Similar results were evident in our study. It is established that development of GDM shares the same risk factors as GH. To avoid bias, we matched variables that could affect BP prior to intervention (there was similar insulin resistance between two groups), and found no significant difference in glycemic control between the two groups although SBP and DBP remained higher in women prescribed insulin. The results also imply the effect of insulin of increasing BP independently of changes in glycemia and insulin resistance.

Insulin is currently considered first-line therapy for glycemic control in pregnant women. Nonetheless it may not be the best option for GDM since it does not alter the pathophysiology. New medicine needed to be developed or found which can improve the pathophysiology of GDM and be safety for mothers and fetus.

There were some limitations of this study. All subjects were derived from one center and this may have led to biased results. Expanding the sample size or using a reliable rodent model of GDM is needed to delineate the effect and mechanism of insulin therapy on pregnancy.

\section{Conclusions}

In summary, our study indicated that insulin therapy was safe for the fetus, and had a slight effect on maternal weight with short-term use but remarkably increased maternal BP. When insulin is used to control glycemia, clinicians should take care to monitor maternal BP and weight gain if long-term use is being considered.

\section{Abbreviations}

GDM: Gestational diabetes mellitus; ADA: American Diabetes Association; BMl: Body mass index; GH: Gestational hypertension; OGTT: Oral glucose tolerance test; BP: Blood pressure; GWG: Total gestational weight gain; SBP: Systolic blood pressure; DBP: Diastolic blood pressure; HOMA IR: Homeostatic Model Assessment of Insulin Resistance; HOMA $\beta$ : Homeostatic Model Assessment of Insulin Sensitivity; BG: Blood glucose
\end{abstract}

\section{Acknowledgements}

We would like to thank all people who helped us in this project.

\section{Authors' contributions}

SZ researched data. TS wrote the manuscript and researched data. LZ and JL reviewed/edited the manuscript. FW and SZ contributed to discussion and reviewed/edited the manuscript. FM, YL, RZ, ZY and XH contributed to data collection. All authors critically revised the manuscript, agree to be fully accountable for ensuring the integrity and accuracy of the work, and read and approved the final manuscript. JL is the guarantor.

\section{Funding}

This study received support from Shanghai Municipal Health Commission Foundation (202040386), the Medical Key Faculty Foundation of Shanghai (ZK2019B15), Scientific Research Project funded by Shanghai Municipal Science and Technology Commission (21S31901800), Key Medical Specialty funded by Shanghai Fifth People's Hospital, Fudan University (2018WYZD004) and The Shanghai Plan for Women and Children's Health Service Capacity Construction (Enhancing the Service Capacity of Shanghai Women and Children Health Care Institutions).

\section{Availability of data and materials}

All data and material used and/or analyzed during the current study are not publicly available but are available from the corresponding author on reasonable request.

\section{Declarations}

Ethics approval and consent to participate

The Ethics Committee of Shanghai Fifth People's Hospital approved this study (Number: 2020 Ethics Approval. No. 154). This work is a retrospective study. Only clinical data of patients were analyzed so informed consent was not required. The study was conducted in accordance with the rules of ethics committee of Shanghai Fifth People's Hospital. Access and use of the medical records were permitted by the medical department and information center of Shanghai Fifth People's Hospital.

\section{Consent for publication}

Not applicable, as above.

\section{Competing interests}

The authors declare that they have no conflicts of interest.

\section{Author details}

'Department of Endocrinology, Shanghai Fifth People's Hospital, Fudan University, 801 Heqin Road, 200240 Shanghai, China. ${ }^{2}$ Department of Radiology, Shanghai Fifth People's Hospital, Fudan University, 801 Heqin Road, 200240 Shanghai, China. ${ }^{3}$ Department of Obstetrics and Gynecology, Shanghai Fifth People's Hospital, Fudan University, 801 Heqin Road, 200240 Shanghai, China.

Received: 28 February 2021 Accepted: 20 August 2021

Published online: 27 September 2021

\section{References}

1. American D, Care AJD. 2. Classification and Diagnosis of Diabetes: Standards of Medical Care in Diabetes-2019. Diabetes Care. 2019;42:13-28. https://doi. org/10.2337/dc19-S002.

2. Catalano PM, McIntyre HD, Cruickshank JK, McCance DR, Dyer AR, Metzger BE, Lowe LP, Trimble ER, Coustan DR, Hadden DR, Persson B, Hod M, Oats JJ. The hyperglycemia and adverse pregnancy outcome study: associations of GDM and obesity with pregnancy outcomes. Diabetes Care. 2012;35(4): 780-6. https://doi.org/10.2337/dc11-1790.

3. Tam WH, Ma RCW, Ozaki R, Li AM, Chan MHM, Yuen LY, Lao TTH, Yang X, Ho CS, Tutino GE, Chan JCN. In Utero Exposure to Maternal Hyperglycemia Increases Childhood Cardiometabolic Risk in Offspring. Diabetes Care. 2017; 40(5):679-86. https://doi.org/10.2337/dc16-2397.

4. Ovesen PG, Jensen DM, Damm P, Rasmussen S, Kesmodel US. Maternal and neonatal outcomes in pregnancies complicated by gestational diabetes. a nation-wide study. J Matern Fetal Neonatal Med. 2015;28(14):1720-24. https://doi.org/10.3109/14767058.2014.966677.

5. Yogev $Y$, Xenakis EM, Langer $O$. The association between preeclampsia and the severity of gestational diabetes: the impact of glycemic control. Am J Obstet Gynecol. 2004;191(5):1655-60. https://doi.org/10.1016/j.ajog.2004.03. 074.

6. Ehrenberg HM, Durnwald CP, Catalano P, Mercer BM. The influence of obesity and diabetes on the risk of cesarean delivery. Am J Obstet Gynecol. 2004;191(3):969-74. https://doi.org/10.1016/j.ajog.2004.06.057.

7. Teh WT, Teede HJ, Paul E, Harrison CL, Wallace EM, Allan C. Risk factors for gestational diabetes mellitus: implications for the application of screening guidelines. Aust N Z J Obstet Gynaecol. 2011;51(1):26-30. https://doi.org/1 0.1111/j.1479-828X.2011.01292.x.

8. Balsells M, Garcia-Patterson A, Sola I, Roque M, Gich I, Corcoy R. Glibenclamide, metformin, and insulin for the treatment of gestational diabetes: a systematic review and meta-analysis. BMJ. 2015;350:h102. https:// doi.org/10.1136/bmj.h102.

9. Jansson N, Rosario FJ, Gaccioli F, Lager S, Jones HN, Roos S, Jansson T, Powell TL. Activation of placental mTOR signaling and amino acid transporters in obese women giving birth to large babies. J Clin Endocrinol Metab. 2013;98(1):105-13. doi:https://doi.org/10.1210/jc.2012-2667.

10. Tarry-Adkins JL, Aiken CE, Ozanne SE. Neonatal, infant, and childhood growth following metformin versus insulin treatment for gestational 
diabetes: A systematic review and meta-analysis. PLoS Med. 2019;16(8): e1002848. https://doi.org/10.1371/journal.pmed.1002848.

11. Seravalle G, Grassi GJHBP, Prevention C. Sympathetic Nervous System, Hypertension, Obesity and Metabolic Syndrome. High Blood Press Cardiovasc Prev. 2016;23(3):1-5. https://doi.org/10.1007/s40292-016-0137-4.

12. Medicine IOJNAP. Weight Gain During Pregnancy: Reexamining the Guidelines. Washington; 2009. http://dx.doi.org/.

13. Obstetrics NJAJo G. Report of the National High Blood Pressure Education Program Working Group on High Blood Pressure in Pregnancy. 2000;183(1): s1-s22. https://doi.org/10.1067/mob.2000.107928.

14. Gutch M, Kumar S, Razi S, Gupta K, Gupta A. Assessment of insulin sensitivity/resistance. Indian J Endocrinol Metabol. 2015;19(1):160. https:// doi.org/10.4103/2230-8210.146874.

15. Metzger BE, Buchanan TA, Coustan DR, de Leiva A, Dunger DB, Hadden DR, Hod M, Kitzmiller JL, Kjos SL, Oats JN, Pettitt DJ, Sacks DA, Zoupas C. Summary and recommendations of the Fifth International WorkshopConference on Gestational Diabetes Mellitus. Diabetes Care. 2007;30 Suppl 2:S251-260. https://doi.org/10.2337/dc07-s225.

16. Ashoush S, El-Said M, Fathi H, Abdelnaby M. Identification of metformin poor responders, requiring supplemental insulin, during randomization of metformin versus insulin for the control of gestational diabetes mellitus. J Obstet Gynaecol Res. 2016;42(6):640-7. https://doi.org/10.1111/jog.12950.

17. Ainuddin J, Karim N, Hasan AA, Naqvi SA. Metformin versus insulin treatment in gestational diabetes in pregnancy in a developing country: a randomized control trial. Diabetes Res Clin Pract. 2015;107(2):290-9. https:// doi.org/10.1016/j.diabres.2014.10.001.

18. Song R, Chen L, Chen Y, Si X, Liu Y, Liu Y, Irwin DM, Feng W. Comparison of glyburide and insulin in the management of gestational diabetes: A metaanalysis. PLoS One. 2017;12(8):e0182488. https://doi.org/10.1371/journal. pone.0182488

19. Saleh HS, Abdelsalam WA, Mowafy HE, Abd ElHameid AA. Could Metformin Manage Gestational Diabetes Mellitus instead of Insulin? Int J Reprod Med. 2016;2016:3480629. https://doi.org/10.1155/2016/3480629.

20. Tertti K, Ekblad U, Koskinen P, Vahlberg T, Rönnemaa TJD, Obesity M. Metformin vs. insulin in gestational diabetes. A randomized study characterizing metformin patients needing additional insulin. Diabetes Obes Metab. 2013;15(3):246-51. https://doi.org/10.1111/dom.12017.

21. Guo L, Ma J, Tang J, Hu D, Zhao XJJoDR. Comparative Efficacy and Safety of Metformin, Glyburide, and Insulin in Treating Gestational Diabetes Mellitus: A Meta-Analysis. J Diabetes Res. 2019(2):1-29. https://doi.org/10.1155/2019/ 9804708.

22. Persson B, Stangenberg M, Hansson U, Nordlander E. Gestational Diabetes Mellitus (GDM): Comparative Evaluation of Two Treatment Regimens, Diet Versus Insulin and Diet. Diabetes. 1985;34(Supplement_2):101-105. https:// doi.org/10.2337/diab.34.2.5101.

23. Coustan DR, Lewis SB. Insulin Therapy for Gestational Diabetes. Obstet Gynecol. 1978;51(3):306-310. https://doi.org/10.1097/00006250-197803000-00010.

24. Liu HY, Cao SY, Hong T, Han J, Liu Z, Cao WJJoBC. Insulin Is a Stronger Inducer of Insulin Resistance than Hyperglycemia in Mice with Type 1 Diabetes Mellitus (T1DM). J Biol Chem. 2009;284(40):27090. https://doi.org/1 0.1074/jbc.M109.016675.

25. Erpeldinger S, Rehman MB, Berkhout C, Pigache C, Zerbib Y, Regnault F, Guérin E, Supper I, Cornu C, Kassaï BJBED. Efficacy and safety of insulin in type 2 diabetes: meta-analysis of randomised controlled trials. BMC Endocr Disord. 2016;16(1):39. https://doi.org/10.1186/s12902-016-0120-z.

26. Niromanesh S, Alavi A, Sharbaf FR, Amjadi N, Akbari SJDR, Practice C. Metformin compared with insulin in the management of gestational diabetes mellitus: A randomized clinical trial. Diabetes Res Clin Pract. 2012; 98(3):422-9. https://doi.org/10.1016/j.diabres.2012.09.031.

27. Wang F, Han L, Hu D. Fasting insulin, insulin resistance and risk of hypertension in the general population: A meta-analysis. Clin Chim Acta. 2017:464:57-63. https://doi.org/10.1016/j.cca.2016.11.009.

28. DeFronzo RA. The effect of insulin on renal sodium metabolism. A review with clinical implications. Diabetologia. 1981;21(3):165-71. https://doi.org/1 $0.1007 / \mathrm{bf00252649.}$

29. Fonseca VA. Insulin resistance, diabetes, hypertension, and renin-angiotensin system inhibition: reducing risk for cardiovascular disease. J Clin Hypertens (Greenwich Conn). 2006;8(10):713-20; quiz 721-712. https://doi.org/10.1111/ j.1524-6175.2006.05583.x.

30. Anderson EA, Hoffman RP, Balon TW, Sinkey CA, Mark AL. Hyperinsulinemia produces both sympathetic neural activation and vasodilation in normal humans. J Clin Investig. 1991;87(6):2246-52. https://doi.org/10.1172/jci115260.

31. Smith MM, Minson CT. Obesity and adipokines: effects on sympathetic overactivity. J Physiol. 2012;590(8):1787-801. https://doi.org/10.1113/ jphysiol.2011.221036.

32. Palei AC, Spradley FT, Granger JPJAJoH. Euglycemic hyperinsulinemia increases blood pressure in pregnant rats independent of placental antiangiogenic and inflammatory factors. Am J Hypertens. 2013;12:1445-51. https://doi.org/10.1093/ajh/hpt137.

33. Wang H, Tian Y, Chen Y, Shen X, Li GJC, Hypertension E. Hyperinsulinemia rather than insulin resistance itself induces blood pressure elevation in high fat diet-fed rats. Clin Exp Hypertens. 2020;5:1-8. https://doi.org/10.1080/1 0641963.2020.1756316.

\section{Publisher's Note}

Springer Nature remains neutral with regard to jurisdictional claims in published maps and institutional affiliations.

\section{Ready to submit your research? Choose BMC and benefit from:}

- fast, convenient online submission

- thorough peer review by experienced researchers in your field

- rapid publication on acceptance

- support for research data, including large and complex data types

- gold Open Access which fosters wider collaboration and increased citations

- maximum visibility for your research: over $100 \mathrm{M}$ website views per year

At BMC, research is always in progress.

Learn more biomedcentral.com/submissions 